\title{
A Model for Prediction of the Buffalo and Cattle male Calves' live Weight
}

\author{
Ibrahim Soliman*
}

\author{
Professor of Agricultural Economics, Faculty of Agriculture, Zagazig University, Zagazig, Egypt
}

\begin{abstract}
The buffalo and cattle population in Egypt reached about 4.898,893 and 3,476,396 heads, respectively, in 2019. The buffalo and cattle meat production represented around $43 \%$ and $45 \%$ of the total meat production in Egypt, respectively, and the average carcass weight of buffalo and cattle reached $318 \mathrm{~kg}$ and $336 \mathrm{Kg}$ in 2019 . About $50 \%$ of livestock numbers are slaughtered off-slaughter houses due to a shortage in the capacity of slaughterhouses and other financial and administrative reasons. The conducted field survey of this study showed that the majority of Egyptian livestock markets lack live weight scales, and if available, they are expensive and frightening for the animals. Therefore, numerous feedlot enterprises hire an agent who can visually forecast the expected live weight of the exhibited feeder calves for sale in the market at a high charge. Most of the models to predict the weight of live cattle-bulls knowing the chest circumference were lacking such models for buffalo-bulls and were linear models that fit only limited periods of cattle-fattening. The sample survey included 500 buffalo males and 340 cattle males of different live weights from 14 villages in 4 provinces in the Nile Delta. The data were used to estimate the best-fitted model for Egyptian livestock. This study showed that the best-fitted model was curved linear. It was a quadratic form. For empirical application, the study designed a table to predict the live weight of buffalo and cattle males at a range of $100-200 \mathrm{~cm}$ chest circumference. The results showed that a $1 \%$ increase in the chest circumference was associated with a $2.4 \%$ and $2.8 \%$ increase in the buffalo and cattle male's circumference, which implicitly reflects higher live weight gain of cattle than buffalo males and better meat quality. Therefore, the farm price of cattle feeder males surpassed the buffalo by $\$ 1000$.
\end{abstract}

Keywords: Prediction Model, Fed Calves, Egyptian Livestock Maekets.

\section{INTRODUCTION}

The buffalo and cattle population in Egypt reached about 4.898,893 and 3,476,396 heads, respectively, in 2019. The total number of slaughtered buffalo and cattle in the same year was about $1,088,548$ and $1,134,412$, respectively, that were compiled and calculated [1], i.e., the off-take rate was around $31.3 \%$ and $23 \%$, respectively. The average carcass weight of buffalo and cattle reached $318 \mathrm{~kg}$ and $336 \mathrm{Kg}$ in 2019 . The buffalo and cattle meat production represented around $43 \%$ and $45 \%$ of the total meat production in Egypt, respectively, which was measured as carcass weight in that year. They were compiled and calculated from [1]. However, about $50 \%$ of livestock are slaughtered off-slaughter houses due to a shortage in the capacity of existing slaughterhouses and high fees that should be paid for such marketing function [2]. Therefrom, numerous feedlot enterprises hire agents at relatively high charge who have experience in guessing the body live-weight of the exhibited calves visually for sale in the livestock market. They, normally, depend upon the morphological traits of the calves, either feeder calves (for fattening) or fed calves (for slaughtering) [3].

*Address correspondence to this author at the Professor of Agricultural Economics, Faculty of Agriculture, Zagazig University, Zagazig, Egypt; E-mail: ibsoliman@hotmail.com
This study conducted a field sample survey at livestock markets of Egypt, as will be shown later. Even though the buffalo and cattle feeder-calves trade is widespread in the Egyptian livestock markets, this survey showed that most Egyptian livestock markets lack scales for liveweight, and if available, weighing animals would be expensive and frightening for the animals. Therefore, numerous feedlot enterprises hire agents at relatively high charge rates to judge or forecast the liveweight of the exhibited salable calves in the market sites. Such a fundamental problem was displayed by most of the respondents who were interviewed at the livestock markets. Pricing and grading in livestock markets require basically knowing the age and live weight of an animal, which apparently, are indicators for the expected, derived carcass weight and its purchase price [2]. The exhibited buffalo and cattle calves and bulls for sale in livestock markets in Egypt are purchased either as feeder calves for feedlot system or finished fed calves for slaughtering.

Fioretti (2012) [4] cited that the ability of farmers to estimate the body liveweight of cattle enables them to evaluate the price and the yield of meat that can be obtained and consequently the expected profit. As castration is forbidden in Egypt by legislation, all feedlot animals are called bulls or male calves as they are within the age of 1-3 years [5]. Therefore, the objective of this study was to estimate a quantitative mathematical model to predict the liveweight of feeder 
or fed buffalo and beef bulls to overcome the obstacles of the lack of animals' body weight scales in most livestock markets and avoid the associated high cost and high risk.

Several recent studies have developed equations to predict the weight of live cattle-bulls knowing the chest circumference. The pioneers in finding such relationships were Brody et al. (1937) [6]. The available literature has shown a strong correlation between chest circumference and cattle live body weight. Such relation helped develop equations to predict the weight of live animals, knowing the circumference of the chest $[7,8]$.

However, all previous studies had applied such a relationship on cattle rather than buffalo. Secondly, they classified the cattle and designed a linear relationship between body liveweight and chest circumference. Therefore, this study aimed to estimate mathematical models for buffalo bulls and beef bulls in Egypt's livestock markets that fit all-male classes, either by age or body weight. The final target of this objective was to design a scale-measure "digital-bar" associated with a list in a table to show different values for the circumference of the chest corresponding to each live weight. Even if a scale were available in the market, it would be much easier to measure the chest's perimeter than loading the animal on a scale, particularly if it has not passed through such an operation before.

\section{DATA AND METHODOLOGY}

The sample was a "multistage stratified random sample from Lower Egypt (Nile delta region). The $1^{\text {st }}$ stage included the selected providences, and the $2^{\text {nd }}$ stage included the districts where the main livestock markets are located. The two strata represent the livestock type (buffalo and cattle bulls). Even though the ability of respondents to participate in the research work and the limited budget allocated for the study had limited the sample size, it was a reasonably larger size than the sample size of several previous studies dealing with this issue. The sample size and structure are presented in (Table 1). Data were collected on the chest circumference and liveweight of buffalo and cattle males from villages in districts within the frontiers of 6 provinces "Sharkia, Qalyoubia, Monoufia, Kafr Al Sheikh, Gharbia and Giza". The sample size included 500 buffalo males and 340 cattle males, as shown in (Table 1).

A recent study has designed a linear model for predicting zebu cattle live weight using live animal measurements by using a total of 247 Sudanese indigenous cow-bulls [7]. The cow-bulls live weights ranged from 170 to $390 \mathrm{Kg}$. The study revealed that heart circumference around the hump had the highest correlation coefficient with live weight $(r=0.83$, $p<0.001$ ) compared with other body measurements. Grouping data according to live weight indicated that heart circumference around the hump in group B (medium weight) and $\mathrm{C}$ (heavyweight) had shown that the closest correlation coefficient with live weight was $r$ $=0.66$ and 0.86 , respectively. The authors concluded that their results gave more confidence in using the former measurement to predict the live weight of humped cattle. The regression analysis of live weight on heart circumference around the hump was highly significant $(P<0.001)$, and the regression lines indicated a linear relationship. The regression equations were also obtained to estimate the live weight of the "heavy", "medium", and "light" weight bulls. The general equation for prediction of live weight of the humped cattle was as follows:

Table 1: Structure of the Field Sample Survey

\begin{tabular}{|c|c|c|c|}
\hline Province & Number of Villages & Cattle Bulls & Buffalo Bulls \\
\hline \hline Al Sharqya & 3 & 187 & 213 \\
\hline Al Qalyoubia & 4 & 30 & 157 \\
\hline Al Monofia & 5 & 38 & 50 \\
\hline Al Giza & 2 & 40 & 0 \\
\hline Kafr Al Sheikh & 2 & 45 & 0 \\
\hline Al Gharbia & 2 & 340 & 500 \\
\hline Total & 18 & & \\
\hline
\end{tabular}

Source: compiled from the sample survey data. 
$Y=2.4573 x-92.472( \pm 0.36)$, Where: $Y=$ live weight

$(\mathrm{Kg})$ and $X=$ heart circumference around the hump $(\mathrm{cm})$.

However, the present study on cattle and buffalo bulls in Egyptian markets considered the concept around the mathematical form of the model applied by the pioneer study of Brody et al. (1937) [6]. This is because of the large sample size they introduced in the estimation. They showed that in the case of data representing different growth stages and age groups, the non-linear power (allometric) equation (double-log equation) gave the best-fitted model for that kind of data. The relation between body weight and chest circumference of dairy cattle of mixed ages may be formally represented by the following equation:

$\mathrm{Y}=\mathrm{a} \mathrm{X}^{\mathrm{n}}$

Where $\mathrm{Y}$ is bodyweight and $\mathrm{X}$ chest circumference.

The value of the exponent " $\mathrm{n}$ " was of the order 2.82 , i.e., the percentage increase in body weight tended to be about 2.82 times as great as the percentage increase in chest circumference, but the estimated model of that study for each of the 6 groups of investigated cattle showed that the values of " $n$ " ranged from 2.72 to 2.88 . There were also variations within groups and with size in the value of the intercept coefficient "a". It appeared that the relationship between weight and chest circumference was not altogether independent of nutritional level. However, the relation between weight and chest circumference was close enough to estimate weight from chest circumference. For the theoretical generalization and within certain weight limits, a power function of chest circumference as indicated by the equation $Y=a X^{n}$ was satisfied. It was fitted by the method of least squares for the weight-chest pairs of measurements.

The current study considered the nonlinearity adopted by Brody et al. [6] in estimating the target model. They showed in their article that " within certain limits of liveweight, a power function of chest circumference as indicated by the equation $Y=a x^{n}$ was satisfied. Therefore, this study also estimated a function of the quadratic form (polynomial function) to cover almost all bodyweight range of buffalo males and cattle males exhibited for sale in the livestock markets. Accordingly, both models were estimated to choose the best-fitted one for buffalo and cattle bulls in the Egyptian livestock market.

\section{Power Function}

The following mathematical function was applied to estimate the relationship between the liveweight $\left(Y_{i}\right)$ and the chest circumference $\left(X_{i}\right)$

$Y_{i}=a x_{i}^{b}$

Where:

$Y_{i}=$ liveweight in $\mathrm{kg}$ of livestock type $\mathrm{i}$

$X_{i}=$ Chest circumference in $\mathrm{cm}$ of livestock type $\mathrm{i}$

$\mathrm{a}=$ the intercept in $\mathrm{kg}$

$\mathrm{i}=\mathrm{b}$ for buffalo bull $\mathrm{c}$ for cattle bull $=\mathrm{c}$

$b=$ Coefficient of response (regression coefficient) as the relative change in live weight associated with $1 \%$ change in chest circumference.

The power function is a non-linear transitional form that can be transformed to linear form by the logarithmic transformation of equation (1) to estimate its parameters (equation 2).

$\operatorname{Ln}\left(Y_{i}\right)=\operatorname{Ln}(a)+b \ln \left(X_{i}\right)$

Where $\mathrm{Ln}=$ natural logarithm of the variable(s)

\section{Polynomial Function}

The other version of the model was estimated by applying the Polynomial regression equation, where only two terms were introduced, which were the linear term and the quadratic one (Equation 3)

$Y_{i}=a+b_{1} x_{i}+b_{2} x_{i}$

Where:

$Y_{i}, X_{i}$, and $a=$ were Defined the same as in equation (1)

$b_{1}, b_{2}=$ Estimated response coefficients of live weight to the chest circumference

\section{RESULTS AND DISCUSSION}

The basic descriptive statistical estimates of the sample (The range and SD) were presented in (Table 2). It displays the value of the minimum, maximum, and standard deviation of the chest circumference and liveweight of the number of heads of buffalo and cattle bulls in the drawn sample. 
Table 2: Min., Max., and SD of the Sample Data for the Concerned Variables

\begin{tabular}{|c|c|c|c|}
\hline \multirow{2}{*}{ Livestock Type } & Variable & \multicolumn{2}{|c|}{ Range } \\
\cline { 3 - 5 } & & Minimum & Maximum \\
\hline \hline \multirow{2}{*}{ Buffalo Male } & Liveweight (Kg) & 100 & 334 \\
\cline { 2 - 5 } & Chest Circumference (CM) & 102 & 175 \\
\hline \multirow{2}{*}{ Cattle Male } & Liveweight (Kg) & 93 & 420 \\
\cline { 2 - 5 } & Chest Circumference (CM) & 100 & 181 \\
\hline
\end{tabular}

Source: compiled and calculated from the sample survey data.

The clear difference between the maximum live weight of the sampled buffalo males and the cattle sampled males reflected the wide variation in cattle breeds in the Egyptian market of Holstein, Friesian, and their crossbred with native cattle. Such variation was shown by the much larger value of the standard deviation of cattle male's liveweight and chest circumference.

As the estimated model was applied for both buffalo and cattle males, either as male feeder calves or fed bulls, the results and associated discussions were presented under two sections. Each was allocated for one type of animal.

\section{Buffalo Male Calves and Bulls}

Whereas equation (4) shows the estimated power form of the buffalo male calf and bull's model and its linear transformation in equation (5), equation (6) shows the estimated quadratic form of the buffalo male calves and bull's model. The values in parentheses under the estimates of the parameters of each equation are the SE of the corresponding regression coefficient.

$Y_{b}=0.0009 X_{b}^{2.4744}$

$$
\left(R^{2}=0.9451\right)
$$

$\operatorname{Ln}\left(Y_{b}\right)=-7.018977+2.474352 \ln \left(X_{b}\right)$

$Y_{b}=201.997108-3.674401\left(X_{b}\right)+0.025245\left(X_{b}^{2}\right)$

$$
(1.09450) \quad(0.0071) \quad\left(R^{2}=0.9501\right)
$$

Both buffalo models provided evidence that the relation between the liveweight and chest circumference of a buffalo male is not of a linear form. It is either a non-linear (Power) form or a curve-linear form (polynomial). Despite the slightly larger value of $\mathrm{R}^{2}$ of the quadratic form, it was selected because it is more suitable and easier for empirical use than a nonlinear equation (powder form), particularly within a wide range of livestock ages and live weights. The t-test indicated that the regression coefficients derived from the two models' forms were statistically significant at a significance level of less than $5 \%$.

Table 3 shows the predicted values of the liveweight of buffalo males for meat production by measuring the male chest circumference using the quadratic equation (6). Figure 1 compares the actual and predicted values of Buffalo male's liveweight, derived from applying equation (6). The results showed that the differences between the actual and predicted liveweight were not apparent, i.e., the estimated values have almost coincided with the observed ones. The study recommends applying such a metric scale to get the body liveweight of buffalo males. Even though it is recommended to repeat such work on a larger sample that includes Upper Egypt livestock markets (southern Egypt's providences).

\section{Cattle Male Calves and Bulls}

Simulating the same models estimated for buffalo, the cattle models were estimated for the cattle where the dominant breed is crossbred of domestic with either Holstein or Frisian. However, about $10 \%$ of cattle male calves and cattle bulls are either pure foreign breeds or traditional (zebu) breeds [3]. Therefore, the field data (Table 2) showed a much higher standard deviation in male cattle weights for sale in the livestock markets than buffalo males. Equations (7) and (8) showed the estimated allometric model, and its linear transformation and equation (9) showed the quadratic model. All estimated response parameters of the estimated models were statistically significant at $<5 \%$ probability level. The quadratic form was selected because of the same reasons mentioned above for the buffalo model. Table $\mathbf{4}$ presents the predicated liveweight of cattle male calves (feeder's calves) and the predicted liveweight of cattle bulls (fed calves). It should be mentioned that the legislations prohibit slaughtering cattle calves of less than $200 \mathrm{Kg}$ 
liveweight. Therefore, the calves up to such weight are considered feeder's calves, i.e., they are sold for fattening and associated with the high sale price.

$y=0.0002 x^{2.8282}$

$(0.052)$

$\left(R^{2}=0.923\right)$

$\ln (y)=-8.657532+2.82808 \ln X$

$y=112.72093-2.83627 X+0.025009 X^{2}$

$$
(0.0654) \quad(0.00822) \quad\left(R^{2}=0.925\right)
$$

The estimated power (allometric) models for both buffalo and cattle provided (Equations 5 and 7) a reasonable criterion for comparing both types of livestock with respect to the relative response of body weight to the change in the chest circumference. This is because such a model's estimated response coefficient is the average relative change in liveweight due to a $1 \%$ change in chest circumference (average elasticity of response). Estimating models (4) and (7) showed that a $1 \%$ increase in the chest circumference was associated with about $2.5 \%$ increase in the liveweight of a buffalo male and a $2.8 \%$ increase in the liveweight of a cattle male. Such a result reflects, implicitly, the slower growth of the buffalo liveweight than cattle. This is because the Egyptian buffalo as a river buffalo strain is mainly a dairy buffalo breed rather than for meat, while the current dominant breed of cattle in the Egyptian market is a dual-purpose breed $[5,9,10]$. Previous studies also showed that the beef as feedlot is of more mumbled and lean meat cuts than

Table 3: Predicted of Buffalo Bull Liveweight at Different Chest Circumferences Measures

\begin{tabular}{|c|c|c|c|c|c|c|c|}
\hline $\begin{array}{c}\text { Chest } \\
\text { circumference } \\
\text { (CM) }\end{array}$ & $\begin{array}{l}\text { Live } \\
\text { Weight } \\
\text { (Kg) }\end{array}$ & $\begin{array}{l}\text { Chest } \\
\text { circumference } \\
\text { (CM) }\end{array}$ & $\begin{array}{c}\text { Live } \\
\text { Weight } \\
\text { (Kg) }\end{array}$ & $\begin{array}{l}\text { Chest } \\
\text { circumference } \\
\text { (CM) }\end{array}$ & $\begin{array}{l}\text { Live } \\
\text { Weight } \\
\text { (Kg) }\end{array}$ & $\begin{array}{l}\text { Chest } \\
\text { circumference } \\
\text { (CM) }\end{array}$ & $\begin{array}{l}\text { Live } \\
\text { Weight } \\
\text { (Kg) }\end{array}$ \\
\hline 100 & 87 & 125 & 137 & 150 & 219 & 175 & 332 \\
\hline 101 & 88 & 126 & 140 & 151 & 223 & 176 & 337 \\
\hline 102 & 90 & 127 & 143 & 152 & 227 & 177 & 343 \\
\hline 103 & 91 & 128 & 145 & 153 & 231 & 178 & 348 \\
\hline 104 & 93 & 129 & 148 & 154 & 235 & 179 & 353 \\
\hline 105 & 95 & 130 & 151 & 155 & 239 & 180 & 359 \\
\hline 106 & 96 & 131 & 154 & 156 & 243 & 181 & 364 \\
\hline 107 & 98 & 132 & 157 & 157 & 247 & 182 & 369 \\
\hline 108 & 100 & 133 & 160 & 158 & 252 & 183 & 375 \\
\hline 109 & 101 & 134 & 163 & 159 & 256 & 184 & 381 \\
\hline 110 & 103 & 135 & 166 & 160 & 260 & 185 & 386 \\
\hline 111 & 105 & 136 & 169 & 161 & 265 & 186 & 392 \\
\hline 112 & 107 & 137 & 172 & 162 & 269 & 187 & 398 \\
\hline 113 & 109 & 138 & 176 & 163 & 274 & 188 & 403 \\
\hline 114 & 111 & 139 & 179 & 164 & 278 & 189 & 409 \\
\hline 115 & 113 & 140 & 182 & 165 & 283 & 190 & 415 \\
\hline 116 & 115 & 141 & 186 & 166 & 288 & 191 & 421 \\
\hline 117 & 118 & 142 & 189 & 167 & 292 & 192 & 427 \\
\hline 118 & 120 & 143 & 193 & 168 & 297 & 193 & 433 \\
\hline 119 & 122 & 144 & 196 & 169 & 302 & 194 & 439 \\
\hline 120 & 125 & 145 & 200 & 170 & 307 & 195 & 445 \\
\hline 121 & 127 & 146 & 204 & 171 & 312 & 196 & 452 \\
\hline 122 & 129 & 147 & 207 & 172 & 317 & 197 & 458 \\
\hline 123 & 132 & 148 & 211 & 173 & 322 & 198 & 464 \\
\hline 124 & 135 & 149 & 215 & 174 & 327 & 199 & 471 \\
\hline
\end{tabular}

Source: Estimated from equation (6). 


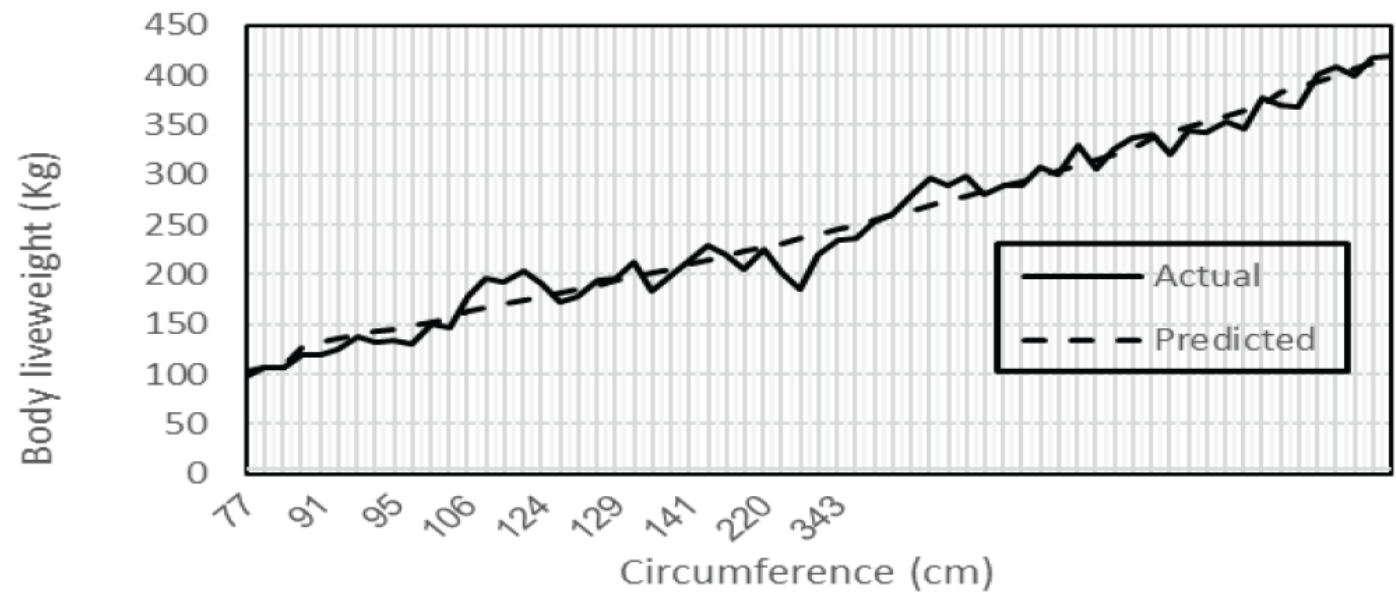

Figure 1: Actual and predicted buffalo bulls body live weight.

Source: Field Survey Data and Equation (9).

Table 4: Predicted of Cattle Bull Liveweight at Different Chest Circumferences Measures

\begin{tabular}{|c|c|c|c|c|c|c|c|}
\hline $\begin{array}{l}\text { Live } \\
\text { weight }\end{array}$ & $\begin{array}{c}\text { Chest } \\
\text { Circumference }\end{array}$ & $\begin{array}{l}\text { Live } \\
\text { weight }\end{array}$ & $\begin{array}{c}\text { Chest } \\
\text { Circumference }\end{array}$ & $\begin{array}{l}\text { Live } \\
\text { weight }\end{array}$ & $\begin{array}{c}\text { Chest } \\
\text { Circumference }\end{array}$ & $\begin{array}{l}\text { Live } \\
\text { weight }\end{array}$ & $\begin{array}{c}\text { Chest } \\
\text { Circumference }\end{array}$ \\
\hline 315 & 163 & 214 & 142 & 136 & 121 & 79 & 100 \\
\hline 320 & 164 & 219 & 143 & 139 & 122 & 81 & 101 \\
\hline 326 & 165 & 223 & 144 & 142 & 123 & 84 & 102 \\
\hline 337 & 167 & 232 & 146 & 149 & 125 & 88 & 104 \\
\hline 342 & 168 & 236 & 147 & 152 & 126 & 91 & 105 \\
\hline 348 & 169 & 241 & 148 & 156 & 127 & 93 & 106 \\
\hline 353 & 170 & 245 & 149 & 159 & 128 & 96 & 107 \\
\hline 371 & 173 & 259 & 152 & 170 & 131 & 103 & 1010 \\
\hline 376 & 174 & 264 & 153 & 174 & 132 & 106 & 111 \\
\hline 382 & 175 & 269 & 154 & 178 & 133 & 109 & 112 \\
\hline 388 & 176 & 274 & 155 & 182 & 134 & 112 & 113 \\
\hline 394 & 177 & 279 & 156 & 186 & 135 & 114 & 114 \\
\hline 400 & 178 & 284 & 157 & 190 & 136 & 117 & 115 \\
\hline 406 & 179 & 289 & 158 & 194 & 137 & 120 & 116 \\
\hline
\end{tabular}

Source: Estimated from Equation (6). 


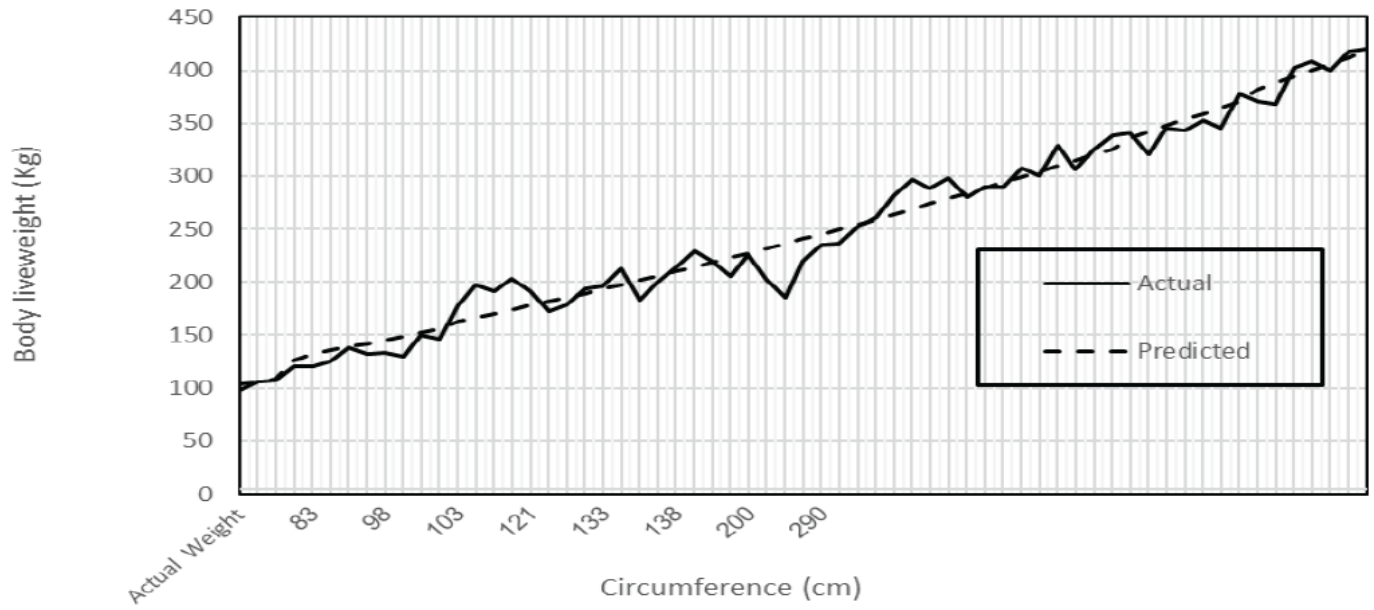

Figure 2: Actual and predicted cattle bulls body live weight.

Source: Field Survey Data and Equation (6).

Table 5: Meat Buffalo and Cattle and Buffalo Liveweight Farm Price (\$/ton)

\begin{tabular}{|c|c|c|c|c|c|c|c|c|c|c|c|c|}
\hline Year & 2008 & 2009 & 2010 & 2011 & 2012 & 2013 & 2014 & 2015 & 2016 & 2017 & 2018 & $\begin{array}{c}\text { Annual } \\
\text { Average }\end{array}$ \\
\hline Buffalo & 3,065 & 2,888 & 3,606 & 3,567 & 4,087 & 3,626 & 3,846 & 3,654 & 2,926 & 2,145 & 2,642 & 3,277 \\
\hline
\end{tabular}

Source: Compiled from: FAOSTAT Data 2-12-2021 Cattle Liveweight Data <fao.org>

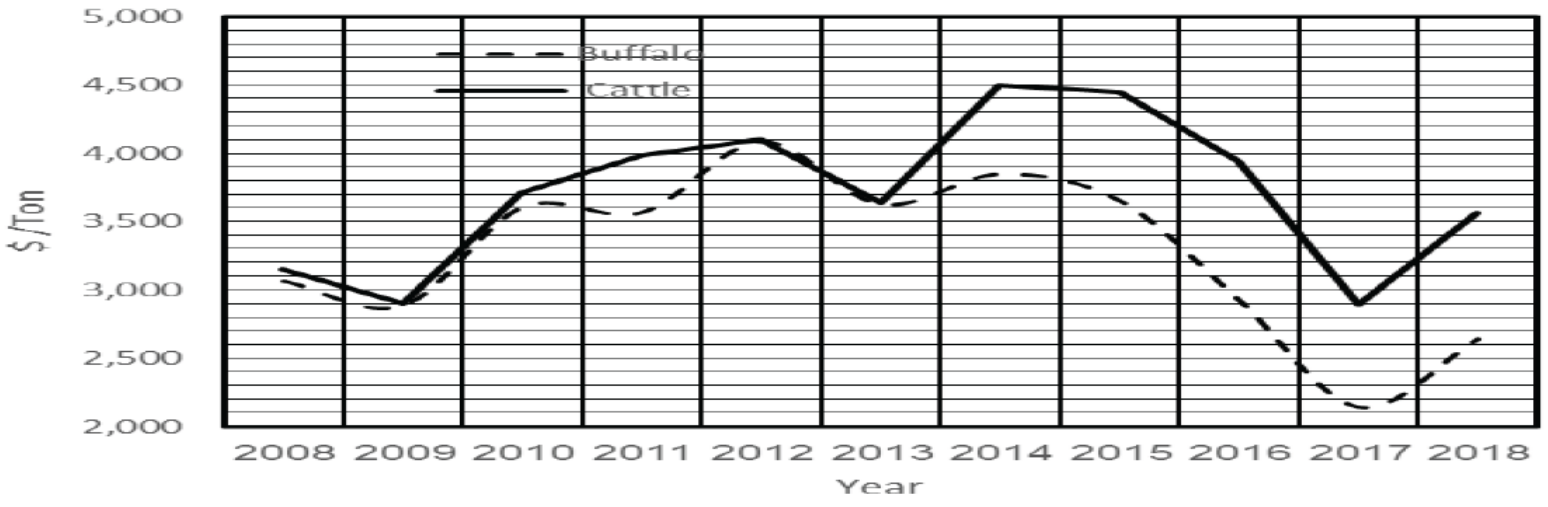

Figure 3: Buffalo and cattle male live weight price.

Source: Table 5.

fattened buffalo males. The higher price per ton liveweight of Cattle bulls liveweight than buffalo males sold (Table 5) and (Figure 3) would also reflect the higher demand for better quality meat cattle feedlot males of faster daily gain liveweight. The annual average farm price/ton (2008- 2018) was about $\$ 3,277$ for buffalo bulls and $\$ 3,711$ for cattle bulls sold. It should be mentioned that the decrease in buffalo and cattle bull's price over the period (2012- 2017) was due to the socioeconomic changes associated with the Arab Spring revolutionary movement which, started on $25^{\text {th }}$ of 2011 in Egypt, even though the prices have returned to increase trend after 2017 (Table 5 and Figure 3). In 2018 the cattle bull's 1-kg liveweight farm price surpassed buffalo price by about $\$ 1000$. In addition, the apparent higher off-take rate of slaughtered buffalo of $31 \%$ than cattle of $24 \%$ was not an efficiency measure. This is because most buffalo males are sold as veal at 2-3 months old before weaning to save buffalo milk of higher price than cow milk in Egypt and save feeds for dairy animals and fattening cattle males of faster daily live weight gain [11]. 


\section{REFERENCES}

[1] FAOSTAT, Food and Agricultural Organization of the United Nations, fao.org Feb. 102021.

[2] Soliman I, Gaber M, Mashhour A. Animal products marketing systems in Egypt. The final report (540 pages), A contracted research project of Zagazig University with the Academy of Scientific Research and Technology (2004-2006), Cairo, Egypt 2006.

[3] Molina-Flores B, Velasco G, Loza S, Soliman I. Socio-cultural factors determining roles and responsibilities in traditional Cattle production systems within rural communities of Upper Egypt. Casasús I, et al. (eds.), Animal farming and environmental interactions in the Mediterranean region, EAAP publication No. 131, (c) Wageningen Academic Publishers 2012; pp. 241-247. https://doi.org/10.3920/978-90-8686-741-7 30

[4] Fioretti, Mauro. An alternative vision-based A system that can calculate the circumference of the chest of cattle to estimate their body weight " Presented at the International Committee for Animal Recording (ICAR) meeting on May 30, in Cork, Ireland 2012.

[5] Soliman I. Present Situation and Future Perspective of Buffalo Production in Africa. The Journal of Animal and Plant Sciences 2012; (4): 657-664.
[6]

Brody S, Davis HP, Ragsdale AC. Relation between Live Weight and Chest Circumference in Dairy Cattle of Unknown Age. University of Missouri College of Agriculture Agricultural Experiment Station, Research Bulletin 262, June 1937.

[7] Abdel Hadi OMA, Babiker SA, Prediction of zebu cattle live weight using live animal measurements. Livestock Research for Rural Development 2009; 21(8).

[8] Khalafalla IEE, Atta M, EI Tahir IE, Mohammed AM. Effect of Body Weight on Slaughtering Performance and Carcass Measurements of Sudan Baggara Bulls. Livestock Research for Rural Development 2011; 23(3).

[9] Soliman I. Buffalo Share in Small Farmer Welfare Under Intensive Agricultural System: The Case Study of Egypt. Buffalo Bulletin 2013; 32(1): 132-140.

[10] Soliman I. Role of Dairy Buffalo in Egypt Food Security. Buffalo Newsletters, Issue No. 23rd, FAO, Rome Italy 2008.

[11] Fitch J, Soliman I. Livestock and small farmer Labor supply. in "Migration, mechanization, and Agricultural Labor Markets in Egypt", Richards A, Martin P, Eds. West-view Press, Boulder, Colorado, USA 1983; pp. 45 -77. https://doi.org/10.4324/9780429047107-3

https://doi.org/10.6000/1927-520X.2021.10.10

(C) 2021 Ibrahim Soliman; Licensee Lifescience Global.

This is an open access article licensed under the terms of the Creative Commons Attribution License (http://creativecommons.org/licenses/by/4.0/) which permits unrestricted use, distribution and reproduction in any medium, provided the work is properly cited. 